Indexed by

\title{
Scopus
}

\section{A STUDY ON INFLUENCE OF ENVIRONMENTAL WORKING CONDITIONS ON WEAR OF A BALL SCREW BASED ON TCVN7699-2-30}

Crossref

\section{School of Mechanical}

Engineering, Hanoi University of Science and Technology, No. 1 Dai Co Viet Rd., Hanoi, ROAD Vietnam

KOBSON

\section{Tuan-Anh Bui}

School of Mechanical

Engineering, Hanoi University of Science and Technology, No. 1 Dai Co Viet Rd., Hanoi, Vietnam

\author{
Van-Hung Pham \\ School of Mechanical \\ Engineering, Hanoi University \\ of Science and Technology, \\ No. 1 Dai Co Viet Rd., Hanoi, \\ Vietnam
}

\section{Duc-Do Le}

School of Mechanical

Engineering, Hanoi University of Science and Technology, No. 1 Dai Co Viet Rd., Hanoi, Vietnam

Key words: ball - screw, wear rate, axial load, rotary speed, longevity, TCVN 7699-2-30 doi:10.5937/jaes0-32506

Cite article:

Duc-Toan T., Van-Hung V., Duc-Do L., Tuan-Anh B. (2022) A STUDY ON INFLUENCE OF ENVIRONMENTAL WORKING CONDITIONS ON WEAR OF A BALL SCREW BASED ON TCVN7699-2-30, Journal of Applied Engineering Science, 20(2), 372 - 376, DOI:10.5937/ jaes0-32506

Online aceess of full paper is available at: www.engineeringscience.rs/browse-issues 


\title{
A STUDY ON INFLUENCE OF ENVIRONMENTAL WORKING CONDITIONS ON WEAR OF A BALL SCREW BASED ON TCVN7699-2-30
}

\author{
Duc-Toan Tran, Van-Hung Pham*, Duc-Do Le and Tuan-Anh Bui* \\ School of Mechanical Engineering, Hanoi University of Science and Technology, No. 1 Dai Co Viet Rd., \\ Hanoi, Vietnam
}

Ball screw in a key component of a machine that affects the performance, accuracy working condition, and lifetime of the machines. Temperature and relative humidity $(R H)$ are two environmental factors that affect the assembly condition and lubrication between surfaces. The study proposed an experimental investigation of the influences of the specific environmental working conditions corresponding to the tropical climate and the Vietnamese standardization system TCVN7699-2-30 on wear of a ball screw with serial No. of PSS1505N1D0261. The results show that the ball screw working in the environmentally lubricated conditions according to the TCVN7699-2-30, the longevity increased by 4.18 times as compared to the ISO 3408-5. The fundamentals for calculation and adjustment of the environmental working conditions of the machines with a purpose of ensuring the most feasible operation accuracy of the machines should be recommended based on specific conditions.

Key words: ball - screw, wear rate, axial load, rotary speed, longevity, TCVN 7699-2-30

\section{INTRODUCTION}

Ball screw is one of the most important means of delivering high precision motion in the industrial devices, such as CNC Machines, Robots, and so on. The transmission performance and lifetime of ball screw would be decreased after a working time because the wear of ball screw can increase the backlash of a ball screw. As a result, it may directly affect the accuracy operation of the systems. In addition, the machines working outside of the common environmental conditions may lead to the system fails, which is because of the changes in assembly condition of machine parts, lubrication properties between surfaces, and characteristic of forces, torques of the machines. Wear of machine parts during working process will reduce the accuracy, performance, and lifetime of the machines. Thus, estimating the wear rate of machine parts is a critical issue, which is important not only in the field of scientific research but also in the practical manufacturing and mechanical processing. Besides, the accuracy of mechanical products is one of the most significant determinants of a product's price. There are many studies related to the causes of friction pair wear that have been conducted including environmental factors. The effect of pressure and sliding speed on the wear of friction pairs have been presented in several published studies. However, the influences of environmental factors such as environmental temperature and humidity on the wear of friction pairs have been only mentioned in a few kinds of research. In 2011, Ryuta Sato proposed a method to estimate the wear of ball screw and support bearing based on servo signals in a feed drive system. In which, the proposed estimation method is not influenced by the loading mass during the working process
[1]. Chin-Chung Wei et al. presented a new model of wear analysis of the offset type of preloaded ball screw working at a high speed. The results showed that the axial wear depth increases with an increasing operating stroke and rotational speed. Besides, a high ellipticity ratio of contacting asperities on a raceway, which can effectively reduce the increasing rate of wear in an offset type preloaded ball-screw, was also indicated in the study [2]. In addition, a study on the wear of a ball screw based on the feed motor current was presented by Xing Liu et al. in 2016. It is proposed a method to observe the wear condition of a ball screw and also to avoid the interferent influence of the environment on the ball screw [3]. In 2018, De-Shin Liu et al. presented a study on the influence of environmental temperature on the dynamic behavior of a ball screw. A finite element simulation model with ambient temperature changing in a range of $5-55$ ${ }^{\circ} \mathrm{C}$ for a ball screw working at speeds of $50-1000 \mathrm{rpm}$ was proposed. The results showed that the torque depends on the environmental temperature and rotational speed. Hence, at a speed of $1000 \mathrm{rpm}$ and the temperature increasing from 5 to $55^{\circ} \mathrm{C}$, the torque reduces by approximately $75.6 \%$ [4]. In 2020, Chang-Guang Zhou et al. proposed a model to estimate the wear coefficient of double-nut ball screws by considering the wear mechanism at the ball-raceway contact. There are two distinct wear periods with wear coefficients lower than the experimental wear coefficient for continuous sliding friction between steel and steel [5]. Besides, it is also proposed a model for predicting the preload degradation of double-nut ball screws in both theoretical and experimental analysis that may be used to predict the performance and service life of the ball screws in another study [6]. A degradation analysis of ball screw mechanism was 
proposed by Qiang Cheng et al. with consideration of time-varying motion and loading working conditions. A dynamic contact force and a dynamic sliding and rolling behaviors between the ball and the raceway were described. The effectiveness of the accuracy degradation analysis for the ball screw mechanism was demonstrated [7]. Based on the empirical equations for the friction torque of rolling bearings, a new model for predicting the mechanical efficiency of ball screws was proposed by Chang-Guang Zhou et al. [8]. According to the study, the mechanical efficiency of ball screws increases with increasing axial load at a rotational speed of $1000 \mathrm{rpm}$. The friction coefficient of ball screws is also a factor that can be used to analyze the performance of the ball screws. A model to estimate friction torque in a ball screw system was proposed by D. Olaru et al. The authors presented a program that can investigate the influences of the speed and load on total friction torque [9]. In 2019, Lu-Chao Zhang and Li Zu presented a method to calculate the friction coefficient of ball screws based on the thermal equilibrium. The authors showed the same tendency of temperature raise between the theoretical calculation and experimental result so that can be used to evaluate the mechanical efficiency [10]. Nguyen Anh Tuan et al. have presented the effect of Vietnam climate with relative humidity changing from $60 \%$ to $100 \%$ on wear of iron and steel materials. The authors showed that the wear increases rapidly with relative humidity [11]. The environment around the world is very diverse and complex based on geographic regions. The international standard ISO has confirmed the influence of temperature and humidity on the error of machine parts by a regulation of uniform temperature and relative humidity in measurements. The environment with a high relative humidity (such as from $90 \%$ to $100 \%$ in the spring), combining with high rate of temperature change (about $50 \mathrm{C} / \mathrm{h}$ ), and a high amount of temperature variation in a day is a severe weather style in the world but it appears frequently in the North of Vietnam, especially from January to March. These environmental conditions have been described in the standard IEC 60068-2-30 and it is completely equivalent to a standard of Vietnam called TCVN 7699-2-30 [12]. Ball screw is a high-precision part unit in a CNC machine, which directly decides the accuracy of the workpiece fabricated in the machine, especially working in those climatic conditions. This manuscript presents the results of an experimental study on the effects of temperature and humidity on the wear of a ball screw used in a CNC machine under the impact of loads and speeds with environmental conditions corresponding to the TCVN 7699-2-30.

\section{EXPERIMENT PROCEDURE}

\section{Experiment conditions}

To investigate the influence of environmental conditions in the experiments, a ball screw with serial No. of PSS1505N1D0261 was used for the experiment system.
The experiment was conducted to determine the effects of axial load and rotational speed of the screw to wear rate of the ball-screw with the working condition according to the standard TCVN 7699-2-30. The experimental time for wear survey was a 24-hour cycle working in the environment following TCVN 7699-2-30. The load and rotational speed applied to the ball screw in these experiments correspond to the values of load and working speed on an actual CNC machine with the same ball screw transmission. Assuming the ball-screw is used on a CNC drill to drill the largest $12 \mathrm{~mm}$ diameter hole in cast iron with a maximum feed rate of $12 \mathrm{~mm} / \mathrm{rev}$. Then, the maximum axial force acting on the ball screw can be calculated as approximately $3500 \mathrm{~N}$. When the feed rate is smaller, the force on the ball screw is also correspondingly small. This force is also reduced when machining holes with smaller diameters. In this study, the rotation speed range of the ball screw suitable for the above machining tasks is around $78-100 \mathrm{rpm}$. The suitable axial force for this machining can range from $2500-3500 \mathrm{~N}$. Hence, the axial loads and rotational speeds used in the experiments are described in Table 1.

Table 1: Axial load and rotational speed used in the experiments

\begin{tabular}{|c|c|c|}
\hline No & $\begin{array}{c}\text { Axial Load } \\
\mathrm{Fa}(\mathrm{N})\end{array}$ & $\begin{array}{c}\text { Rotary speed } \\
\mathrm{n}(\mathrm{rpm})\end{array}$ \\
\hline 1 & 3500 & 100 \\
\hline 2 & 3500 & 78 \\
\hline 3 & 3000 & 89 \\
\hline 4 & 2500 & 100 \\
\hline 5 & 2500 & 78 \\
\hline
\end{tabular}

The wear rate of a ball screw under different speed and load conditions can be determined on the basis of a theoretical regression function, as follows [13]:

$$
\gamma=a_{0} \times F^{a_{1}} \times n^{a_{2}}
$$

\section{Where}

$$
\begin{array}{ll}
\mathrm{V}: & \text { Wear rate, determined by } \mathrm{y}=\mathrm{U} / \mathrm{t} \\
\mathrm{U}: & \text { Amount of wear }(\mu \mathrm{m}) \\
\mathrm{t}: & \text { Experiment time }(\mathrm{s}) \\
\mathrm{F}: & \text { Axial load }(\mathrm{N}) \\
\mathrm{n}: & \text { Rotational speed of screw shaft }(\mathrm{rpm})
\end{array}
$$

$a_{0}, a_{1}, a_{2}$ : Coefficients depending on working conditions. To determine the empirical regression function, it is necessary to perform the linearization of the function of two variables, so Eq. (1) can be written as follows:

$$
\ln \gamma=\ln a_{0}+a_{1} \ln F+a_{2} \ln n
$$


therefore, new variables of Eq. (2) can be set as $\mathrm{Y}=\ln (\mathrm{Y}) ; \mathrm{A}=\ln (\mathrm{a} 0) ; \mathrm{Z1}=\ln (\mathrm{F}) ;$ and $\mathrm{Z2}=\ln (\mathrm{n})$.

The equation (2) can be written in a new form as:

$Y=A+a_{1} \cdot Z_{1}+a_{2} \cdot Z_{2}$

This relationship has been determined with the specific working conditions as described in Table 1. In addition, the temperature and humidity conditions of the working environment shall correspond to the values specified in the standard TCVN 7699-2-30.

\section{Experiment equipment system}

The experimental system to determine the ball screw wear during the working process has been set up and the diagram is described in Fig. 1. Main parts of the system include (1) a ball screw transmission; (2) a hydraulic system to create load to the nut; (3) a computer-connected measurement system of wear; and (4) a cabinet to create an environment with different temperatures and humidity.

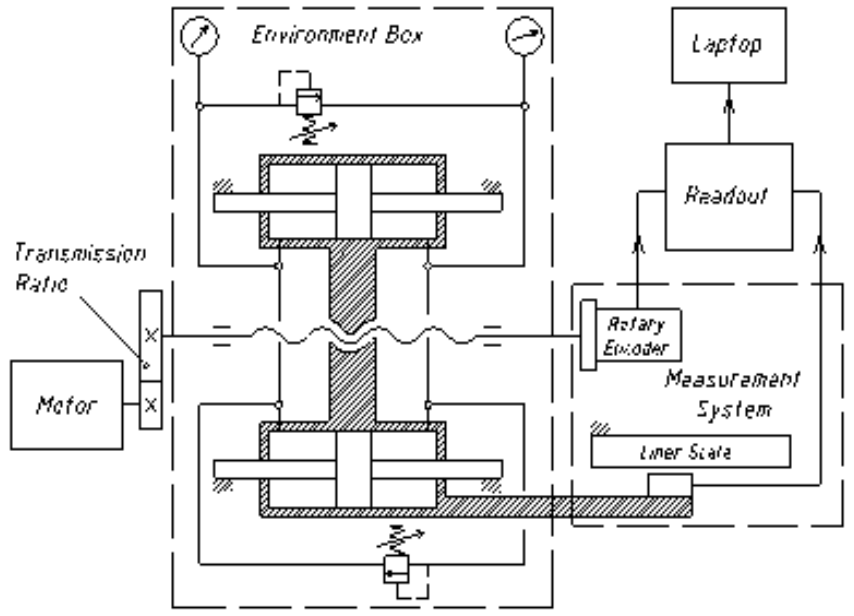

Figure 1: Overall diagram of experiment machine

The rotation speed of the screw is precisely controlled via a frequency converter to reach the experimental values of 78, 89, and $100 \mathrm{rpm}$, respectively. Meanwhile, the axial load placed on the nut is generated from a hydraulic system and adjusted to the required values during the test, the corresponding values of 2500,3000 , and 3500 $\mathrm{N}$. In addition, the hydraulic system is also used to determine the amount of wear through a measuring system (as described in Fig. 1). Especially, the whole experimental system is placed in a thermo-humidity chamber which can adjust the temperature and humidity according to the test requirements. Thus, the humidity can be changed in a range of $51 \div 99 \%$ with an error of $\pm 2 \%$, and temperature can be controlled in a range of $15 \div 49^{\circ} \mathrm{C} \pm 1^{\circ} \mathrm{C}$.

\section{Wear estimation of ball-screw}

A measurement system was used to determine the axial wear, which includes a Linear Encoder (LE) with the precision of $1 \mu \mathrm{m}$. Thus, the amount of displacement of the nut as compared to the position of the table was indicated. A Rotary Encoder (RE) attached directly to the screw shaft was used to determine the amount of angular displacement of the screw shaft with a resolution of 5000 (pulses/rev). The translational and rotary parameters were collected and transferred to a computer through a readout device. The relationship between the axial wear and position deviation of the nut is described as shown in Fig. 2. Accordingly, each part of the ball screw transmission can be considered as an elastic element, then the equivalent model of the transmitter is considered to consist of two springs in series. The length of the part at the start of work is L01 + L02, where one spring corresponds to the amount of wear after a working period, $L_{02}$.

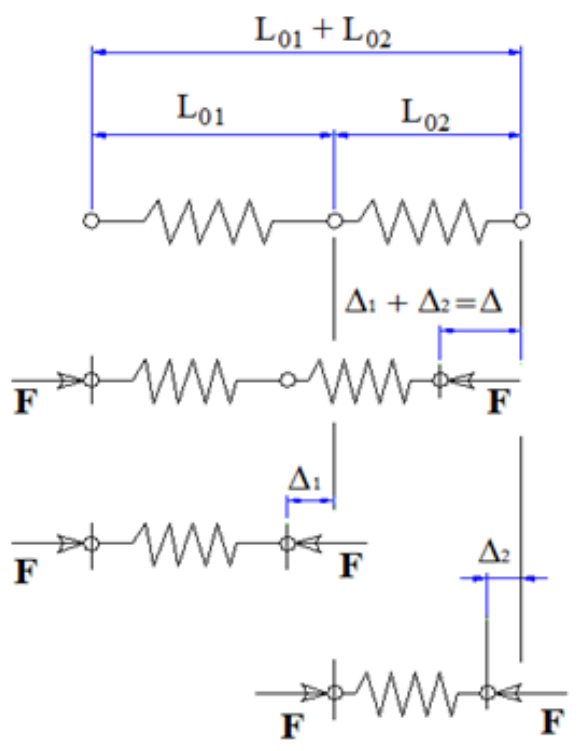

Figure 2: Relationship between axial wear and deviation: L02 - the amount of wear $(\mu \mathrm{m}) ;$ L01 - the length left after wear $(\mu \mathrm{m}) ; \mathrm{F}$ - the axial load $(\mathrm{N})$;

$\Delta_{1}$ - the amount of elastic deformation of $L_{01}(\mu \mathrm{m})$; $\Delta_{2}$ - the amount of elastic deformation of $L_{02}(\mu \mathrm{m})$; $\Delta$ - the elastic deformation before wear $(\mu \mathrm{m})$

Under an axial load $\mathrm{F}$, the system will be deflected to one side due to wear in an amount determined as follows:

$\Phi=\left(L_{02}+\Delta_{1}\right)-\Delta=L_{02}-\Delta_{2}$

Where $\Delta_{2}$ is the amount of elastic deformation of the segment $L_{02}$, which is very small as compared to $L_{02}$, therefore $\Phi$ can be considered as follows:

$\Phi=L_{02}-\Delta_{2} ; \quad L_{02}$ 
The amount of axial wear of a ball -screw can be considered as an amount of deviation in the position of the nut before and after being worn. Based on the standard ISO 230-2, the data was conducted by measuring at 12 target points with an equal interval of 1800 based on the rotation angle of the screw shaft (RE has a resolution of 5000 pulses/rev corresponding to the destination with the equal interval of RE 2500 pulses). Each experiment was repeated ten times for data measurement taken according to chronological order:

+ Starting experiment: data taken at the original location +24 hours after creating wear in the environment based on ISO 7699-2-30

+ At the end of the experiment - after 48 hours of wear in the environment created based on TCVN 7699-2-30. The process of obtaining data of measuring wear was conducted after 1 or 2 cycles under these environmental conditions.

\section{RESULT AND DISCUSSION}

The experiment was conducted in the planning shown in Table 1. Deviation value due to wear after 1 to 2 cycles of temperature and humidity was measured at 12 points and average values of wear were taken. A summary of the amount of wear in each experiment was given in Table 2 .

Table 2: Summary of the amount of wear in each experiment

\begin{tabular}{|c|c|c|c|c|}
\hline 을 & $\begin{array}{c}\text { Axial load } \\
\text { Fa (N) }\end{array}$ & $\begin{array}{c}\text { Rotary } \\
\text { Speed } \\
\mathrm{n}(\mathrm{rpm})\end{array}$ & $\begin{array}{c}\text { Axial } \\
\text { wear } \\
\mathrm{U}(\mu \mathrm{m})\end{array}$ & $\begin{array}{c}\text { Wear rate } \\
\gamma=\frac{\mathrm{U}}{\mathrm{t}}\end{array}$ \\
\hline 1 & 3500 & 100 & 8.28 & 0.172 \\
\hline 2 & 3500 & 78 & 5.60 & 0.117 \\
\hline 3 & 3000 & 89 & 4.10 & 0.086 \\
\hline 4 & 2500 & 100 & 2.86 & 0.060 \\
\hline 5 & 2500 & 78 & 2.26 & 0.047 \\
\hline
\end{tabular}

From the experimental results obtained, the coefficients $\mathrm{a} 0$, a1 and a2 for the regression function to test the dependence of wear rate on the load and rotary speed of ball screw shaft when working in environments of TCVN 7699-2-30 after 48 hours were determined and shown in Fig. 3. The wear rate was estimated by the following expression:

$\gamma_{b t}=1.71 \times 10^{-14} \times n^{1.274} \times F a^{2.945}$

For a ball-screw with a code of PSS1505N1D0261, the dynamic load calculated is $6410(\mathrm{~N})$. The ISO 3408-5 defined longevity when working with load $F=3000(\mathrm{~N})$; speed $n=89$ (rpm) was: $L=3082$ (hours), corresponding to the maximum permissible deviation of the trans- mission were: $\psi \max =2 . e p=62.4(\mu \mathrm{m})$. Therefore, the amount of wear after 24 hours (as defined in ISO 3408) was: $\psi 24=62.4 / 3082.24=0.49(\mu \mathrm{m})$. Comparing the amount of wear in experiment 3 to the amount calculated in accordance with the ISO 3408-5, the results showed that when working in the environment of TCVN 7699-230 with lubricants, the wear rate increase by 4.18 times as compared to that of working in the environment according to the ISO 3408-5.

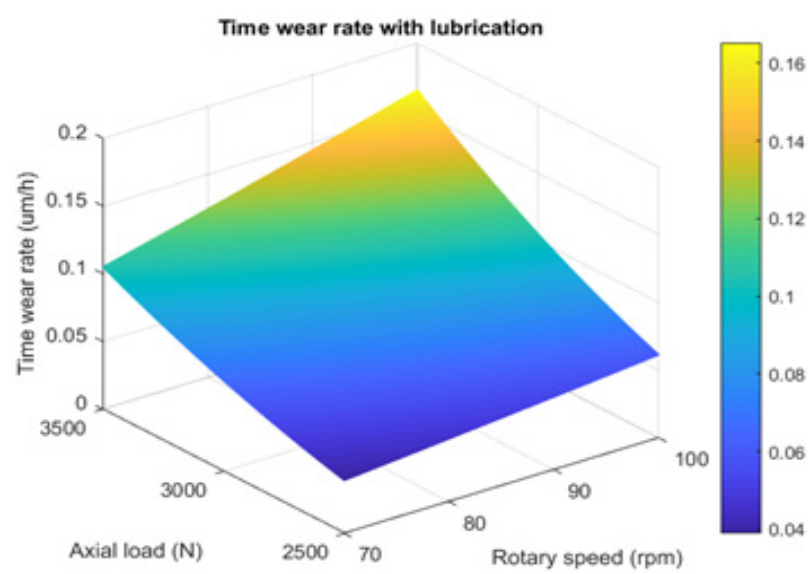

(a)

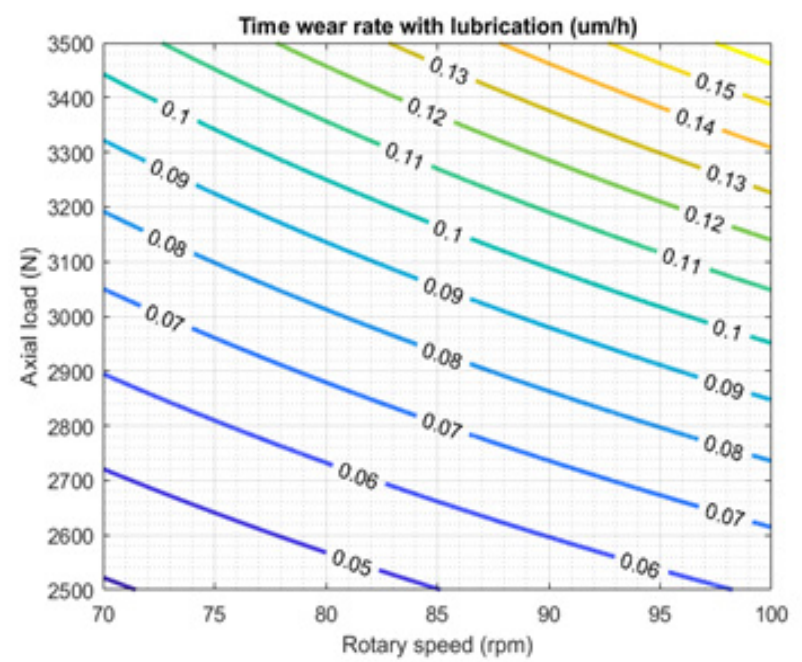

(b)

\section{CONCLUSION}

The experiment system with working environment conditions according to temperature and humidity of TCVN 7699-2-30 to evaluate the influence of these working environments on the wear of a ball screw with a serial No. of PSS1505N1D0261 has been successfully built. The experimental study showed that the influence of loads and rotary speeds on wear of ball-screw is expressed by Eq. (4). In addition, with the environmental condition following TCVN7699-2-30 with lubricants, the longevity increased by 4.18 times as compared to the ISO 3408-5. The results can be the fundamentals for the calculation and adjustment of the environmental working conditions of the machines to ensure the most feasible operation accuracy of the machines. 


\section{ACKNOWLEDGEMENTS}

This research is funded by Vietnam Ministry of Education and Training under project number B2021-BKA-13.

\section{REFERENCES}

1. Sato R., (2011). Wear estimation of ball screw and support bearing based on servo signals in feed drive system. Leading Edge Manufacturing in 21st century : LEM21, p. 3233.1-3233.6.

2. Wei C.-C., Liou W.-L., Lai R.-S. (2012). Wear analysis of the offset type preloaded ball-screw operating at high speed, Wear, vol. s 292-293, 111-123, DOI: 10.1016/j.wear.2012.05.024.

3. Liu X., Mao X., He Y., Liu H., Fan W., Li B., (2016). A new approach to identify the ball screw wear based on feed motor current. Proceedings of the International Conference on Artificial Intelligence and Robotics and the International Conference on Automation, Control and Robotics Engineering, p. 1-5.

4. Liu D.-S., Lin P.-C., Lin J.-J., Wang C.-R., Shiau T.-N. (2019). Effect of environmental temperature on dynamic behavior of an adjustable preload double-nut ball screw, The International Journal of Advanced Manufacturing Technology, vol. 101, no. 9-12, 27612770, DOI: 10.1007/s00170-018-2966-x.

5. Zhou C.-G., Zhou H.-X., Feng H.-T. (2020). Experimental analysis of the wear coefficient of double-nut ball screws, Wear, vol. 446-447, 1-12, DOI: 10.1016/j.wear.2020.203201.

6. Zhou H.-X., Zhou C., Feng H.-T., Ou Y. (2020). Theoretical and experimental analysis of the preload degradation of double-nut ball screws, Precision Engineering, vol. 65, 72-90, DOI: 10.1016/j.precisioneng.2020.04.012.
7. Cheng Q., Liu Z., Zhang C., Xue D. (2019). An accuracy degradation analysis of ball screw mechanism considering time-varying motion and loading working conditions, Mechanism and Machine Theory, vol. 134, 1-23, DOI: 10.1016/j.mechmachtheory.2018.12.024.

8. Zhou C.-G., Feng H.-T., Ou Y. (2018). A new model for predicting the mechanical efficiency of ball screws based on the empirical equations for the friction torque of rolling bearings, Advances in Mechanical Engineering, vol. 10, no. 9, 1-8, DOI: 10.1177/1687814018800173.

9. Olaru D., Puiu G. C., Balan L. C., Puiu V. (2005). Chapter 20. D. Talabă and T. Roche, Product Engineering: Eco-Design, Technologies and Green Energy. Springer Netherlands, Dordrecht, p. 333-346.

10. Zhang L.-C., Zu L. (2019). A new method to calculate the friction coefficient of ball screws based on the thermal equilibrium, Advances in Mechanical Engineering, vol. 11, no. 1, 1-5, DOI: 10.1177/1687814018820731.

11. Tuan N. A., Y N. D., Van Hung P., Thai N. N. (1993). The wear of material in humid-tropical conditions, Wear, vol. 162-164, 1066-1067, DOI: 10.1016/00431648(93)90124-5.

12. TCVN 7699-2-30 : 2007 Environmental testing - Part 2-30: Tests - Test A: Damp heat, cyclic $(12 \mathrm{~h}+12 \mathrm{~h}$ cycle) (2007).

13. Nguyen A.-T., Pham V.-H. (2005). Tribology. Science and Technics Publishing House, Hanoi. 